\title{
"MUNDOS IDEALES", UN PROYECTO DE INVESTIGACIÓN E INCIDENCIA EN EL CONTEXTO DE LA PANDEMIA DEL COVID-19 EN MÉXICO
}

\section{"Ideal Worlds", a Research and Intervention Project in the CONTEXT OF COVID-19 PANDEMIC}

Fecha recepción: 18 de abril de 2021 / fecha aceptación: 28 de mayo de 2021

\author{
Luis Alberto Pérez-Amezcua ${ }^{1}$, Verónica Concepción Macías Espinosa², \\ José Isabel Campos Ceballos ${ }^{3}$, Rosa María Alonzo González ${ }^{4}$ \\ y Martha Gabriela Mendoza Camacho 5
}

Cómo citar este artículo:

Pérez-Amezcua L. A., Macías Espinosa V. C., Campos Ceballos J. I., Alonzo GonzálezR.M.yMendozaCamachoM.G.(2021). “Mundosideales”, un proyecto de investigación e incidencia en el contexto de la pandemia del COVID-19 en México. Revista Pensamiento y Acción Interdisciplinaria, 7(1), 76-96. http://doi.org/10.29035/pai.7.1.76

\section{Resumen}

Este artículo describe el proceso de adaptación que ha debido realizarse a un proyecto de investigación e incidencia cuya finalidad es el establecimiento de comunidades de indagación para promover la lectoescritura como herramienta de inclusión social en niños que cursan los últimos años de educación primaria en México. El proyecto respondió a una convocatoria específica del Consejo Nacional de Ciencia y Tecnología de este país publicada antes de la emergencia sanitaria provocada por el COVID-19, por lo que el plan inicial no pudo seguirse una vez que el proyecto fue aprobado y financiado. Dado que la investigación daba por supuesta la cercanía física, en estas páginas se recoge la experiencia de los cambios debidos a la distancia a que obligaron las instituciones por la pandemia. Al final se discuten algunos hallazgos del trabajo de campo con fines diagnósticos y algunas de sus implicaciones.

Palabras claves: Ciencias sociales y humanas, Investigación cualitativa, Procesos de lecto-escritura, COVID-19, Investigación-acción

\footnotetext{
1 Licenciado en letras hispánicas, maestro en estudios de literatura mexicana, doctor en humanidades, Centro Universitario del Sur de la Universidad de Guadalajara, Ciudad Guzmán, Jalisco, México. Correo electrónico: perez.amezcua@cusur.udg.mx 2 Licenciada en psicología, maestra en psicología con orientación en calidad de vida y salud, Centro Universitario del Sur de la Universidad de Guadalajara, Ciudad Guzmán, Jalisco México. Correo electrónico: veronica.macias@cusur.udg.mx

3 Licenciado en lingüística, maestro y doctor en ciencias humanas con especialidad en estudios de las tradiciones, Tuxpan, Jalisco, México. Correo electrónico: profesorcamposceballos@gmail.com

4 Licenciada en comunicación social, maestra en ingeniería con especialidad en sistemas de calidad y productividad, doctora en ciencias sociales, Colima, Colima, México, Correo electrónico: rosmia.glez@gmail.com

5 Licenciada en letras españolas, maestra en estudios de literatura mexicana, maestra en creación artística, doctora en imagen, arte, cultura y sociedad, Cuernavaca, Morelos, México. Correo electrónico: magame0@gmail.com
} 


\begin{abstract}
This article describes the adaptation process that had to be carried out in a research and intervention project whose purpose is to establish inquiry communities to promote literacy as a tool for social inclusion in children who are in the last years of primary education in Mexico. The project responded to a specific call from the National Council of Science and Technology of this country published before the health emergency caused by COVID-19, so the initial plan could not be followed once the project was approved and funded. Given that the research took physical proximity for granted, these pages collect the experience of the changes due to the distance that the institutions forced due the pandemic. At the end, some findings of the field work for diagnostic purposes and some of their implications are discussed.
\end{abstract}

Keywords: Social and human sciences, Qualitative research, Reading and writing process,

COVID-19, Action research

\title{
Introducción
}

El Consejo Nacional de Ciencia y Tecnología (Conacyt) es un organismo público descentralizado del Estado mexicano encargado de articular las políticas públicas y promover el desarrollo de la investigación científica. El 22 de noviembre de 2019 este organismo emitió una convocatoria para la elaboración de propuestas de proyectos de investigación e incidencia orientados al fomento de la lectoescritura como estrategia para la inclusión social con el objetivo de "comprender y afrontar tanto el analfabetismo como el analfabetismo funcional en México, fomentar el lenguaje escrito, crítico y analítico, y favorecer la inclusión educativa" (Conacyt, 2019a, p. 1). Estos proyectos se enmarcarían en el programa 5, Educación, de los Programas Nacionales Estratégicos (Pronaces), que "organizan los esfuerzos de investigación en torno a problemáticas nacionales concretas que, por su importancia y gravedad, requieren de una atención urgente y de una solución integral, profunda y amplia" (Conacyt, s/f). Se atendió a dicha convocatoria con la propuesta "Mundos ideales: proyecto interinstitucional y multidisciplinar de fomento a la lectoescritura para la inclusión social de la niñez", un proyecto de investigación e incidencia con la expectativa de contribuir a crear hábitos de lectura y escritura alternativa desde una perspectiva multimodal (Cassany, 2005; Groenke y Prickett, 2012) en los niños y niñas participantes, quienes se esperaba fuesen expuestos a un medio promotor de un ambiente que dé un papel central a los espacios generadores de procesos de lectoescritura crítica y participativa.

Los resultados de la convocatoria se dieron a conocer el 4 de mayo del 2020 (Conacyt, 2020) y "Mundos ideales" fue uno de los veintinueve proyectos aprobados a nivel nacional para la primera fase, con una duración de cuatro meses a partir de la ministración de los recursos, lo que ocurrió hasta noviembre del mismo año. De este modo, esta fase concluiría en marzo de 2021 con una propuesta en extenso que podría ser desarrollada en una segunda fase, en caso de ser aprobada, por un periodo de hasta tres años con un presupuesto mayor (Conacyt, 2019, p. 4). No obstante, debido a las condiciones de la pandemia, se 
otorgó una prórroga para que la primera fase del proyecto - al que el Consejo Ilama, como a los otros, "semilla" - concluya el 30 de abril de 2021, fecha a partir de la cual se contaría con un periodo de 15 días hábiles para la entrega de un informe técnico y uno financiero.

Paralelamente, el 30 de marzo de 2020 el gobierno de México publicó en el Diario Oficial de la Federación el "Acuerdo por el que se declara como emergencia sanitaria por causa de fuerza mayor, a la epidemia de enfermedad generada por el virus Sars-Cov2 (COVID-19)" (DOF, 2020) ante el aumento del número de casos. Aunadas a esta y otras declaratorias parecidas en los estados de la república, diversas acciones fueron indicadas para mitigar el impacto de la pandemia, entre las cuales destacó la suspensión de clases en todos los niveles educativos. En Jalisco, entidad en la que se desarrolla el proyecto de investigación e incidencia, las clases fueron suspendidas por la Secretaría de Educación desde el 17 de marzo del 2020 (Gobierno de Jalisco, 2020). Esta situación se mantuvo hasta el 1 de marzo de 2021, aunque se ha implementado un Programa de Seguimiento Académico (PSA) con grupos reducidos de máximo nueve estudiantes por aula que "tomarán clases de regularización y actividades culturales y deportivas por un máximo de cuatro días cada dos semanas" (EFE, 2021).

El equipo de investigación aplicó un diagnóstico piloto semanas antes de que se oficializara el PSA, por lo que se realizaron gestiones y preparativos sin saber de la implementación de este. Esta experiencia de la fase piloto y ajustes al proyecto es la que se detalla a continuación.

\section{Marco referencial}

El proyecto "Mundos ideales" parte de la convicción de que la infancia no es sólo un periodo de vida, sino un grupo social diferenciado que vive en una realidad que a su vez alude a realidades distintas, contextuales y dinámicas, pues se trata de realidades que no son estables a lo largo de los años, por lo que es posible encontrar en la infancia aspiraciones para el futuro social, igualmente dinámicas (Casas, 1998). Intervenir en esta capacidad de aspiración constituye el núcleo del proyecto.

Por otra parte, la infancia es la etapa en la que se consolida principalmente el potencial del ser humano. Todas las habilidades - desde las cognitivas y psicomotoras hasta las emocionales y sociales - se inician y desarrollan en ese periodo de la vida. La infancia, además, es un periodo especial puesto que, en este, todo es posible gracias a la imaginación. Sin embargo, en la actualidad, e independientemente del estado socioeconómico, la niñez es un grupo vulnerable por el clima mundial de descuido, violencia y explotación desmesurada, lo que limita su adecuado desarrollo y la garantía de sus derechos. Por otro lado, si bien tanto a escala global como en México se ha avanzado en los índices de alfabetización, con base en la UNICEF "el 38\% de los niños salen de la escuela 
primaria sin aprender a leer, escribir y hacer cálculos aritméticos simples" (2016, p. 42); aunado a otras problemáticas contextuales, el analfabetismo afectará la capacidad de las niñas y niños para tener más oportunidades en todos los ámbitos, en la toma de decisiones y la participación democrática, crítica y activa en sus entornos cotidianos.

Las niñas y los niños han sido privados de su derecho a imaginar un país y un mundo mejores y a sentirse parte de la posibilidad de la construcción de estos; además están expuestos de manera continua a los discursos de los adultos de los que únicamente son receptores sin posibilidad de diálogo (UNICEF, 2013). Este proyecto de investigación e incidencia considera a las niñas y a los niños como los actores principales del proceso de construcción horizontal y colectiva no sólo de conocimiento, sino de escenarios futuros. Se considera que un análisis cualitativo respecto a cómo los niños pueden participar como constructores de una cultura para la paz y la colaboración permitirá contribuir a la generación y aplicación de conocimiento para mejorar los índices educativos y de lectura, objetivo hacia el cual deben articularse los esfuerzos de todos los sectores del país.

En lo particular, "Mundos ideales" tiene un antecedente directo: el del trabajo realizado por Tiz Creel, artista visual y conceptual mexicana, y algunos de los miembros del equipo del Programa Universitario de Fomento a la Lectura "Letras para Volar" en el año 2016, quienes tenían el objetivo inicial de fomentar la imaginación y la expresión artística de los niños. Realizaron un estudio piloto en el que además participaron estudiantes y egresados de diferentes carreras. La actividad consistió en realizar un ejercicio artístico en el que se solicitó a siete niños de una escuela primaria del sector público de la ciudad de Guadalajara que representaran su mundo ideal haciendo uso de magnetos con imágenes (imagen 1) que podían distribuir libremente en los pizarrones metálicos de la institución. Las imágenes de los magnetos fueron creadas con base en algunos de los elementos propuestos en la Agenda de Naciones Unidas para el Desarrollo Sostenible para el año 2030 (NU, 2020) así como en la Convención sobre los Derechos de los Niños (UNICEF, S/f) propuesto por la UNICEF desde 1989. 
Imagen 1.

Magnetos con imágenes para la construcción del "mundo ideal"

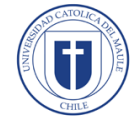

80

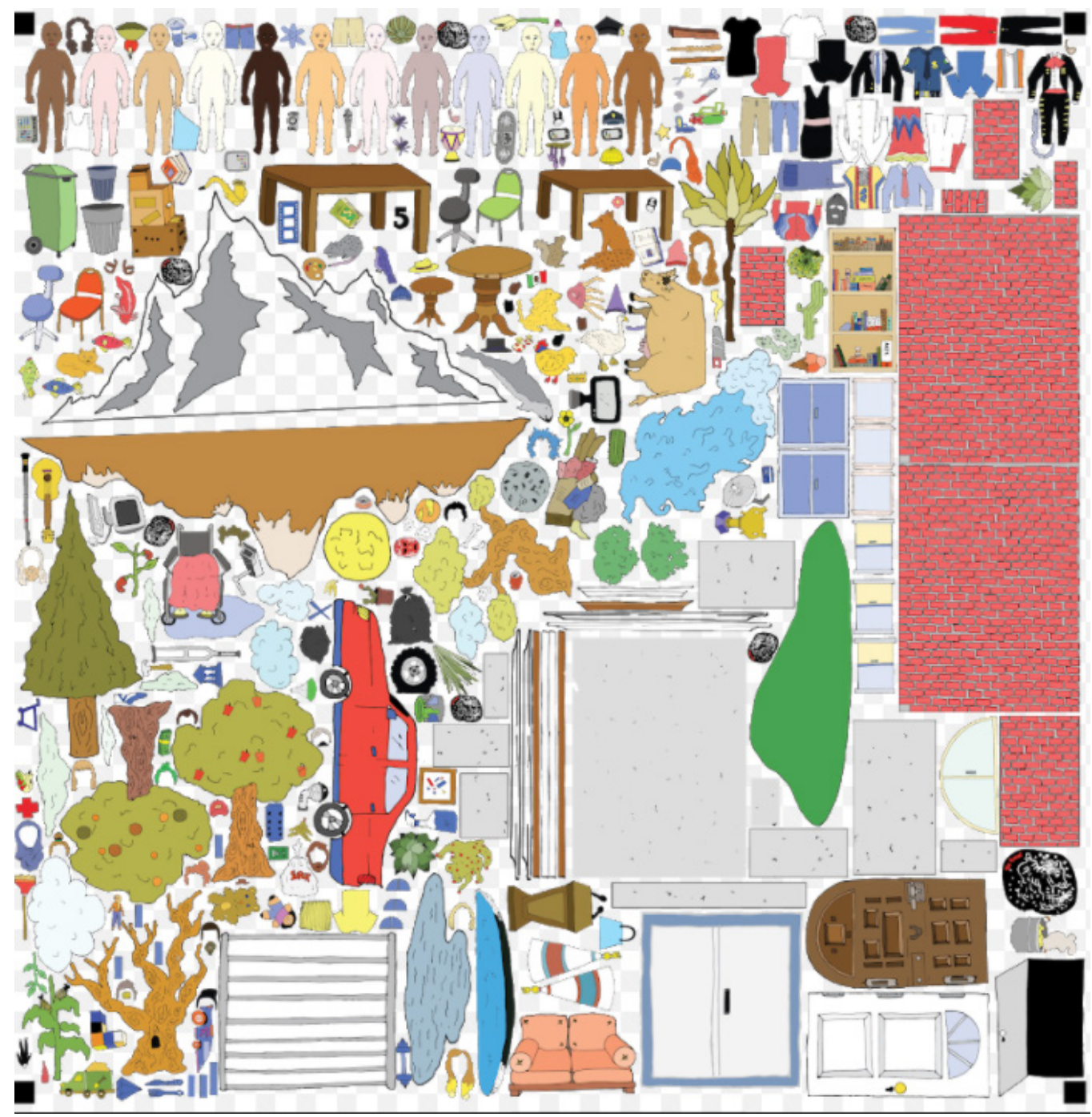

Elaboradas por Creel (2016).

Luego de ese primer intercambio con los niños y las niñas, las representaciones fueron analizadas con el fin de determinar el resultado. Con ello, se llegó a la conclusión de que era posible identificar patrones respecto de las problemáticas que se presentaron con mayor frecuencia en las construcciones visuales de los niños y las niñas. Éstas serían la base para la selección de lecturas mediante las cuales se abordarían las temáticas que destacaran en sus representaciones en el proyecto que lo continuó. Entre las construcciones figuró la preocupación por el medio ambiente y la seguridad, por dar algunos ejemplos (imagen 2). 


\section{Imagen 2.}

Construcción del "mundo ideal" de uno de los niños en la que se observa a un ladrón a la derecha

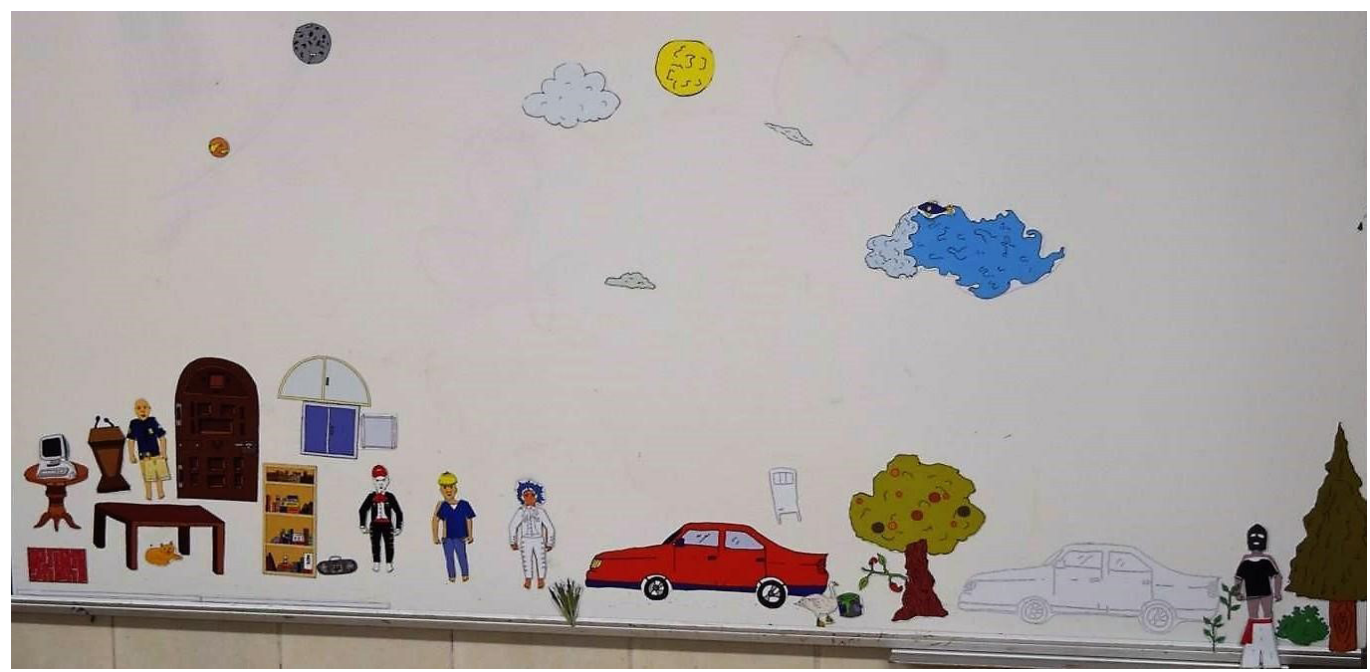

Elaborado por "niño 4" (2016).

El estudio piloto esperaba obtener básicamente dos resultados: 1) que el niño expresara libremente su creatividad a través de los medios gráficos creados por la artista y 2) que a través de dicha expresión el niño reflejara sus necesidades de participar en la sociedad identificando las principales problemáticas que le impiden vivir en su mundo ideal. De acuerdo con sus diseños visuales, se pudo entrever que el instrumento, además de fomentar una expresión libre y creativa, podría ser útil para el diagnóstico de problemas con los que los niños conviven, y que la intervención mediante la lectura puede ser una herramienta para que los niños y las niñas desarrollen el empoderamiento sobre dichas problemáticas, haciéndolos capaces de proponer soluciones y de participar de ellas (imagen 3).

Se concluyó entonces que si bien la expresión creativa es fundamental, era necesario un complemento para la puesta en marcha de estrategias para atender las problemáticas detectadas y apoyar el desarrollo integral y las literacidades de los niños. El proyecto realizado por la artista Tiz Creel ya no pudo continuar debido, en gran medida, a la agenda de los miembros del equipo del Programa Universitario de Fomento a la Lectura "Letras para Volar" y a que Creel emigró al Reino Unido. 


\section{Imagen 3.}

Construcción del "mundo ideal" de una niña en la que se observan libros e instrumentos musicales

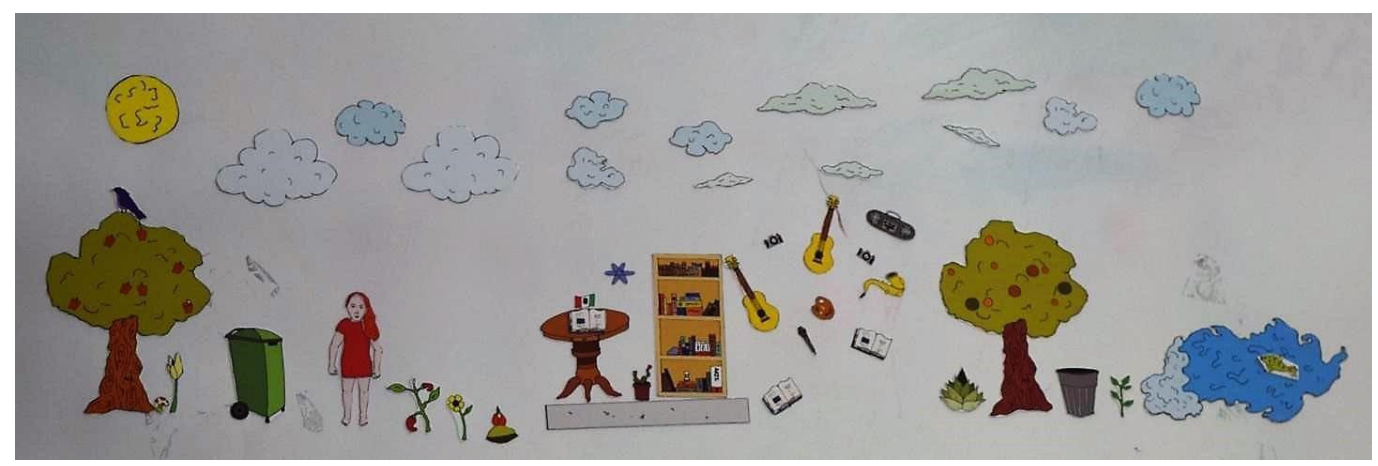

Elaborado por "niña 3" (2016).

Al publicarse la convocatoria del Conacyt se discutieron las posibilidades de participación y se determinó que "Mundos ideales" podría dar respuesta a esa necesidad de atención a los niños y encajar en lo que la institución estaba buscando, por lo que se integró un equipo base que sustentara el proyecto y buscara a colegas de otras instituciones que estuviesen interesados en colaborar, pues entre los requisitos establecidos en los "Términos de referencia" se hallaba el de demostrar las intenciones de vinculación de: 1) investigadores o grupos de investigación de por lo menos dos universidades, 2) asociaciones civiles u otras organizaciones sociales involucradas y comprometidas en la promoción de la lectura y de la lectoescritura y 3) autoridades escolares y/o de cualquier nivel de gobierno con la capacidad y disposición de tomar decisiones a favor de la promoción de una educación para la inclusión (Conacyt, 2019b, p. 2).

Para desarrollar el proyecto se partió de la idea de que un proyecto de investigación-acción, con bases cualitativas y constante reflexión sobre los hallazgos empíricos, sería de utilidad para, en una primera fase, realizar un diagnóstico piloto para la niñez participante que permitiera 1) estudiar su representación y su capacidad de aspirar y 2) conocer sus contextos familiares y socioculturales. A partir de los resultados del diagnóstico se proyecta el diseño de las fases siguientes del proyecto que implican a la incidencia a través de la lectura y actividades artísticas para ampliar la capacidad de aspirar y fomentar la inclusión en los temas presentes en los imaginarios de las niñas y los niños y la evaluación de la misma.

Para contar con un marco referencial se revisaron proyectos de investigaciónacción de corte cualitativo cuyo propósito es el de indagar en los imaginarios y, concretamente, en la percepción a futuro que se tiene en la niñez (11 a 12 años) como grupo de estudio. Villanen y Jonsson (2013) examinan cómo los niños ven el futuro y señalan la importancia de las relaciones intergeneracionales para 
un mayor desarrollo sostenible. Así mismo, los aportes de Martínez-Ezquerro y Martos (2018) subrayan la importancia de la lectura para formar ciudadanos críticos y participativos proponiendo un modelo sociocrítico que toma en cuenta "claves intertextuales e intermodales" con el fin de desarrollar el juicio crítico en los lectores.

También se destacaron trabajos que consideran la influencia de las variables contextuales en la representación del mundo futuro de niños y niñas, entre ellos el de Vega Casanova y García Posada (2005), que aporta datos interesantes cuando se comparan "los imaginarios de ciudad en los niños y las niñas" de distintos estratos sociales; el de Martínez (2017), que aborda cómo se construye el género durante la educación infantil en los entornos escolares; y finalmente el de Luna-Reyes, Herrera-Mijangos y Escobar (2019), que se interesa en la experiencia migratoria en niños y niñas con padres y madres migrantes.

Finalmente, los aportes de Jiménez y Mancinas (2009), Dulama, Ilovan y Vanea (2009), Evans (2015), Arizpe y Styles (2016), Mannay (2017) y Ardévol y Muntañola (2004) son útiles en tanto que proporcionan herramientas conceptuales y metodológicas que nos ayudan a reflexionar sobre el conocimiento por la horizontalidad y la escucha empática durante la fase etnográfica y acerca de la inclusión de las imágenes y narrativas visuales como instrumento metodológico para recuperar las diferentes representaciones sobre los mundos ideales en el grupo etario que nos ocupa.

\section{Metodología}

El proyecto "Mundos ideales" tiene el propósito de desarrollar un instrumento diagnóstico mediante el cual se puedan detectar elementos significativos en las representaciones del mundo ideal, que permita diseñar e implementar una mediación de lectoescritura confiable, dinámica y flexible, capaz de adaptarse y mejorarse continuamente de acuerdo con las diferencias contextuales y que dé cuenta de las necesidades de los niños y niñas que cursan la llamada "primaria mayor". Los niños y niñas beneficiarios de "Mundos ideales" se encuentran en la "etapa de realismo", la cual se caracteriza por sus representaciones más fieles a la realidad, no se limitan a imitar, sino que experimentan, exploran e inventan, obteniendo como resultado una representación más significativa, además, se encuentran alejados del pensamiento egocéntrico y se presenta en ellos la preocupación por los otros y por la causalidad de las cosas (Jiménez y Mancinas, 2009; Rodríguez, 1986).

La niñez participante es quien construye su mundo ideal a través de representaciones visuales.Por lo anterior, se planeó que la mitad de la población muestra lo haría mediante dibujo, mientras que la otra mitad por medio de unos imanes con dibujos pre-elaborados, para en un segundo momento comparar la construcción de las representaciones. En ambos casos, su representación visual 
sería complementada mediante un relato escrito acerca del mismo, además de una entrevista abierta sobre su representación visual. Los beneficiarios directos - público meta - serían niñas y niños estudiantes de quinto y sexto grado de primaria, de 11 y 12 años de edad, provenientes de un total de cuatro escuelas primarias del sector público del estado de Jalisco: dos escuelas de Ciudad Guzmán así como dos escuelas de Guadalajara. De ambas ciudades participa una escuela del turno matutino y otra del turno vespertino.

Mediante "Mundos ideales" se espera el impactar positivamente en los niños y niñas participantes, fortaleciendo las habilidades de pensamiento crítico, conciencia social y empoderamiento, a través de prácticas de expresividad creativa, lectura y escritura en los niños de nivel primaria, lo que ampliará sus oportunidades para participar de la vida ciudadana de manera crítica y democrática en la sociedad (cultura de paz, resolución de problemas, equidad de género, entre otras temáticas).

En junio de 2020 comenzaron los trabajos de "Mundos ideales" a través de la plataforma Meet de la comunidad de indagación (Bocaranda-Santos, 2009), que entonces estaba integrada por 1) un equipo de investigación e incidencia, análisis y supervisión, 2) un equipo aplicador y 3) un equipo de intervención lectora compuestos por profesores de la Universidad de Guadalajara, pertenecientes al Centro Universitario del Sur (CUSur), con sede en Ciudad Guzmán, y al Instituto Transdisciplinar en Literacidad (Itrali) del Centro Universitario de Arte, Arquitectura y Diseño (CUAAD), localizado en Guadalajara. El equipo también inició con dos estudiantes de la Licenciatura en Letras Hispánicas del CUSur y dos de la Maestría en Literacidad (MIL) del CUCEA. La idea de la comunidad es que todos los miembros desarrollen competencias para la investigación-acción en el área de la literacidad. Se buscó desde el comienzo la horizontalidad sin distinción de títulos académicos, considerando que cada miembro puede aportar al proyecto y puede asimismo crecer en lo personal y en lo profesional. Desde luego, dado que ha pasado ya casi un año, ha habido algunos cambios en la composición de la comunidad, retirándose algunos miembros y sumándose otros.

Esta etapa ha implicado hasta ahora veintisiete sesiones virtuales (además de tareas y lecturas independientes) para abonar a diferentes aspectos de la investigación, que fueron desde la construcción del objeto de estudio y descripción del problema de investigación, los antecedentes, la metodología y estrategias a implementar, el diseño del instrumento artísticos (imanes) para la etapa diagnóstica, la elaboración de los cuestionarios y la batería de preguntas para las entrevistas, la selección de los participantes, el acondicionamiento del espacio atendiendo las medidas sanitarias para la realización del diagnóstico, etcétera.

Dado que esta investigación es de corte cualitativo se busca recoger información sobre las problemáticas de contexto de participante para después 
intervenir con mayor eficacia a través actividades de mediación lectoescritora. Por ello, se diseñó una batería de preguntas abiertas para las entrevistas con los padres y los niños. El proceso metodológico que se siguió para la elaboración de dicho instrumento-cuestionarios y batería de preguntas- fue el siguiente: primero, entre todos los integrantes de la comunidad de indagación se discutieron, mediante la plataforma Meet, los hallazgos obtenidos en 2016, con el interés de reflexionar sobre las problemáticas que aquejan a la niñez hoy en día. Posteriormente, el equipo de investigación formuló y estructuró preguntas donde se esperaba obtener información en diferentes campos, particularmente sobre los contextos familiares, escolares y socioculturales de los participantes, y con un énfasis en las principales problemáticas que los han aquejado en este contexto de la pandemia, como la modalidad de las clases a distancia y el acceso-dominio de las TIC. Este proceso metodológico fue el punto de partida para el análisis de contenido, y está directamente relacionado con la etapa de incidencia, que es fomentar la participación e inclusión social de la niñez mediante las herramientas de arte, lectura y escritura.

\section{Primeros cambios metodológicos: población y selección de participantes}

Uno de los primeros cambios que se realizaron fue el de la población en donde se realizaría el diagnóstico con los imanes, pues la idea era comparar los resultados de las representaciones de los niños de escuelas del sistema público en Guadalajara (capital del estado con más de cinco millones de habitantes en su área metropolitana) y Ciudad Guzmán (una población al sur del estado con no más de ciento cincuenta mil habitantes). Esto es, de diferentes contextos educativos. Por cuestiones de tiempo y disponibilidad debidas a los retrasos por la pandemia, finalmente sólo se pudo trabajar con niñas y niños de Ciudad Guzmán. Otro de los cambios tuvo que ver con el turno de las escuelas, pues se deseaba indagar respecto de si existen diferencias en este sentido, pues en entrevista con profesores y directivos estos señalaron que sí las hay. Así, sólo fue posible trabajar con niñas y niños del turno matutino. No obstante, cuando las condiciones por la pandemia lo permitan, se aplicarán las fases de diagnóstico, intervención y análisis de acuerdo con lo planeado originalmente, para comparar entre escuelas de diferente turno y contexto geográfico.

El grupo de estudio también cambió en cuanto al grado que cursan, pues se buscaba al principio trabajar con niñas y niños de cuarto a sexto grado. El primer cambio no tuvo que ver con la pandemia, sino con la edad promedio de los niños, pues se buscó que estos tuvieran una madurez que es más probable encontrar en los dos últimos años escolares. Finalmente, y esto sí tuvo que ver con la pandemia, se decidió trabajar sólo con quinto grado, puesto que el retraso hizo que se aproximara el fin del ciclo escolar y sería imposible trabajar la intervención, la incidencia, con los niños de sexto año, quienes irán a secundaria en agosto de 2021. La decisión, pues, se realizó con la esperanza de que, en el peor de los casos, 
sea posible trabajar con los niños durante el siguiente año escolar (2021-2022), para posteriormente aplicar nuevamente el instrumento diagnóstico para ver si hubo impacto de la mediación lectoescritora. La adecuación en la delimitación de las escuelas y grados participantes obedeció, en resumen, a tres factores: 1) la situación de contingencia sanitaria que prevalece en México que impedía el trabajo diagnóstico con mayor número de participantes; 2) la continuidad evaluativa que puede proporcionar la comunidad de indagación y el equipo interdisciplinar a los niños y niñas participantes de quinto grado una vez que ellos se encuentren en sexto; y 3 ) el horizonte de investigación, pues a mediano y largo plazo se pueden incorporar diferentes variables comparativas en función del turno (matutino-vespertino) y región (Ciudad Guzmán y Zona Metropolitana de Guadalajara), lo cual puede enriquecer aún más el análisis sobre la influencia de los contextos familiares y socioculturales en la construcción de los mundos ideales y la lectoescritura. Para la etapa diagnóstica se eligió y trabajó con niños y niñas de quinto grado de la Escuela Primaria Lázaro Cárdenas del Río del turno matutino. Todos los niños y niñas participantes cuentan con 10 años de edad cumplidos.

La selección también sufrió cambios respecto de lo planeado, pues se esperaba trabajar con participantes elegidos de manera aleatoria, atendiendo sólo a la variable de igualdad en el género. Al final, se trabajó con cuatro niñas y cuatro niños que fueron seleccionados por su profesor o profesora. Se trató, nos dimos cuenta, de los niños con mejor aprovechamiento escolar. La percepción que se tuvo es que la institución estaba más preocupada por dar una buena imagen que por atender las solicitudes del equipo de investigación. Se considera, no obstante, que este sesgo de elección no afectará significativamente los resultados generales de las representaciones del mundo futuro de los niños, lo que se comprobará cuando sea posible realizar un segundo diagnóstico. Los participantes se confirmaron luego de que los niños y sus padres atendieron una videoconferencia informativa a través de Google Meet en la que se explicó el proyecto usando una presentación en PowerPoint y en la que se presentaron los integrantes de la comunidad de indagación. La idea original era, como se señaló líneas arriba, elegir un total de dieciséis participantes de quinto año escogidos al azar del listado del total de alumnos de la escuela, pero al final, el director estableció sus propios métodos, ante los que no se pudo ir en contra ante el riesgo de "perder" definitivamente la participación de la escuela. Hubo que conformarse pues con ese mecanismo. Se espera poder eliminar este sesgo en las siguientes aplicaciones diagnósticas. Sólo se realizó un intento para aglutinar la muestra, porque era la única escuela con una cierta apertura y porque todo estaba detenido por la pandemia. Aquí se nota claramente cómo afectó a este proyecto, pues se deseaba trabajar con niños de diferentes capacidades escolares y no únicamente con los que las tienen más desarrolladas.

Como parte del protocolo, en la reunión con padres y niños se les hizo saber los principios éticos y de responsabilidad en la investigación, principalmente en relación a proteger la identidad de los participantes en los avances, reportes o 
artículos de investigación generados por la comunidad de indagación, y a mantener la confidencialidad durante las etapas en que ellos decidan participar. En ese sentido se elaboraron cartas de consentimiento y asentimiento para los padres, madres y niños participantes, mismas que se firmaron una vez que acudieron a la evaluación diagnóstica y contextual. Los resguardos éticos consisten en garantizar el anonimato de niños y padres en todos los procesos, especialmente en las publicaciones de avances o reportes de investigación. Se entregaron copias de resguardos firmados a padres y niños, no se contempló vencimiento de la información, y el resguardo de esta se realizó en físico, en los archivos del Responsable Técnico. Al final se logró la siguiente representatividad de los tres grupos escolares con que cuenta la escuela: tres participantes del grupo $50 \mathrm{~A}$, dos del grupo $50 \mathrm{~B}$, y tres del grupo $50 \mathrm{C}$. Con los padres de los participantes se estableció una comunicación telefónica para agendar fechas y horarios para la evaluación diagnóstica.

Antes, durante y después de las entrevistas individuales se procuró establecer y mantener un diálogo horizontal, cara a cara, así como un ambiente de cordialidad y respeto con cada uno de los participantes; se cuidó de no hacer preguntas invasivas o que transgredieran la vida privada y se hizo hincapié en que no estaban obligados a responder las preguntas de los entrevistadores.

\section{La adecuación del espacio para la etapa diagnóstica}

Ante la situación de contingencia sanitaria, el Responsable Técnico del proyecto gestionó un espacio para la realización de esta fase diagnóstica ante las autoridades del Centro Universitario del Sur (CUSur), al que se encuentra adscrito, de manera que ésta pudiera llevarse a cabo conservando los protocolos de sana distancia para salvaguardar la salud de todos los participantes. El director de la escuela primaria estuvo de acuerdo pero tuvo que consultarlo con el supervisor de la zona y conseguir el permiso. Se diseñó un protocolo en el que se midió la temperatura tanto de los participantes como de los miembros del equipo de investigación, se aplicó gel antibacterial, se desinfectó todo el material, incluidos los imanes, con una solución especial y se usaron cubrebocas y caretas. Se diseñó, en resumen, un protocolo sanitario estricto.

El espacio de trabajo fueron dos aulas contiguas en el edificio $\mathrm{F}$ del CUSur. En una se entrevistó a los padres o madres de los niños y niñas participantes y en la otra se aplicó el instrumento con arte (magnetos con imágenes y dibujos) y las entrevistas a los niños (as) con el fin de obtener la representación de sus mundos ideales e información cualitativa sobre sus contextos familiares y socioculturales. Ambos espacios permitieron desde luego conservar la sana distancia y cuidar los principios de salud e higiene pues no había más de seis personas al mismo tiempo. En un aula se colocaron mesas y sillas para la realización de las entrevistas; y en la otra se acomodaron tres mesas en hilera sobre las cuales se desplegaron los imanes para una mejor apreciación de éstos y para la elaboración de los dibujos 
y cuentos; además, se colocó una plataforma junto al pintarrón sobre la cual se podían subir los niños para tener una mejor altura al momento de acomodar sus imanes.

\title{
Metodología para la evaluación diagnóstica y contextual
}

La estrategia metodológica que se siguió durante la evaluación diagnóstica y contextual de participantes está asentada en un enfoque cualitativo (Álvarez-Gayou, 2003; Vasilachis, 2006) pues durante esta fase se buscó obtener las subjetividades vertidas en las narraciones verbales y las diferentes formas en que los niños y niñas representan sus propios mundos ideales a partir del uso de figuras con imanes, dibujos y relatos escritos. Como señala Vasilachis (2006, p. 24):

\begin{abstract}
La investigación cualitativa es pragmática, interpretativa y está asentada en la experiencia de las personas; además de que supone [...] privilegiar las palabras de las personas, sus creencias, anhelos, valores, deseos o frustraciones, así como la valoración y el intento para descubrir la perspectiva de los participantes sobre sus propios mundos.
\end{abstract}

Para la recolección de la información cualitativa se utilizó: 1) la técnica de la entrevista semiestructurada con los niños, niñas y sus papás o mamás; y 2) el instrumento con arte, es decir, figuras plasmadas en imanes o los materiales para dibujo (colores y hoja blanca). Esto se realizó con el doble propósito de obtener información sobre los contextos familiares, culturales y de acceso, uso y dominio de las TIC de cada niño o niña; y para obtener la representación acerca de "el mundo de sus sueños" por medio de narrativas visuales, verbales y textuales.

La técnica de la entrevista y el instrumento con arte, a través del análisis del contenido, proporcionan información contextual que servirá como punto de partida para la fase de intervención a través de lecturas guiadas. El conocimiento sobre el contexto de cada niño, adquiere relevancia en todas las etapas de la investigación: diagnóstico, intervención y análisis, pues se requiere de un constante diálogo interdisciplinar sobre los datos entre el equipo realizador de entrevistas y aplicador del instrumento, y los estudiantes de letras y especialistas en literacidad que intervendrán por medio de lecturas y actividades artísticas, ya que así se podrá evaluar la construcción del mundo ideal de cada niño, no de manera aislada, sino siempre con respecto al contexto que ellos expresaron en la fase diagnóstica: su imaginario, sus ideales, las problemáticas que observan en su entorno, etcétera.

La duración de las entrevistas con padres de familia estuvo sujeto al tiempo que el niño o niña permaneció realizando la representación de su mundo ideal por medio de los imanes o dibujo, cuento y entrevista, el tiempo estimado fue de tres horas, en algunos participantes el tiempo de su participación fue menor. Durante la 
participación de los niños y niñas se compartieron elementos de su cotidianeidad como el juego, la escuela, la familia, las actividades recreativas, los amigos y las mascotas, por referir algunos. Las entrevistas semiestructuradas a niños y padres permitieron conocer algunos fragmentos o episodios de vida de los participantes, además de conocer sus intereses, expectativas y preocupaciones sobre su entorno y obtener información de su contexto familiar y sociodemográfico, como la estructura familiar, el nivel de estudios y ocupación de los padres, accesibilidad a las TIC en casa, acompañamiento en actividades escolares, etc. Al respecto, Vaca (2000, p. 53) sostiene:

La recolección de narraciones [...] puede constituirse en un método nuclear dentro de las aproximaciones cualitativas en las ciencias sociales y humanas. Permite a los investigadores situarse en un punto crucial entre el testimonio subjetivo de un individuo a la luz de su trayectoria vital, de sus experiencias [y] de su visión particular.

Estos datos cualitativos son cruciales, pues, como señala Angrosino, "la propia información que ellos proporcionen se convertirá en parte del plan de lo que el investigador puede hacer con ellos" (2012, p. 120), y así es que se pretende incidir en el desarrollo de la lectoescritura y en la inclusión social.

\section{Resultados y discusión}

Como se mencionó, la fase diagnóstica estuvo encaminada a proveer de información cualitativa sobre el "mundo de los sueños" y los contextos de cada niño y niña participante, para consecuentemente intervenir por medio de la literatura y la literacidad. La etapa de evaluación diagnóstica y contextual no sólo fue productiva en una dimensión exploratoria, pues se pudo trabajar con todos los niños con quienes se acordó una cita, sino que permitió que se entrevistara a cuatro mamás, un padre de familia y a una maestra de uno de los grupos.

En términos cualitativos, la evaluación diagnóstica y contextual nos provee de datos para realizar un análisis de contenido interdisciplinar en función de posibles variantes: las temáticas representadas en los mundos ideales de cada niño y niña participante (p. e. medio ambiente, familia, valores, tecnologías, etc.); las problemáticas (p. e. contaminación, violencia, maltrato animal) expresadas a través de los magnetos con imágenes, dibujos, cuentos o de manera verbal; sus intereses, gustos y habilidades (p. e. lectura, artes, videojuegos, redes sociales); además de algunos factores contextuales, como tipo de familia y la disponibilidad o accesibilidad al uso de las TIC. Además, la información cualitativa que arrojó el instrumento servirá para diseñar una metodología de análisis visual de cada representación ( $p$. e. número y tipo de elementos, distribución lineal o en perspectiva de las imágenes, y ubicación o proyección temporal: presente o futuro 
de la representación). Aún no se define de manera concreta la estrategia de análisis y cómo se llevará a cabo operativamente, pero se ha hecho una categorización emergente que será la base de un procesamiento mediante el programa Atlas. ti, para lo cual dos de los miembros del proyecto tomaron recientemente un curso impartido por el Centro Profesional de Estudios Aplicados en Investigación Cualitativa (CPEAIC).

Se ofrece aquí, por cuestiones de espacio, sólo un ejemplo de la representación de un mundo ideal por parte de una de las niñas ya en esta fase (imagen 4).

\section{Imagen 4.}

Construcción del "mundo ideal" de la primera niña que participó en la fase diagnóstica

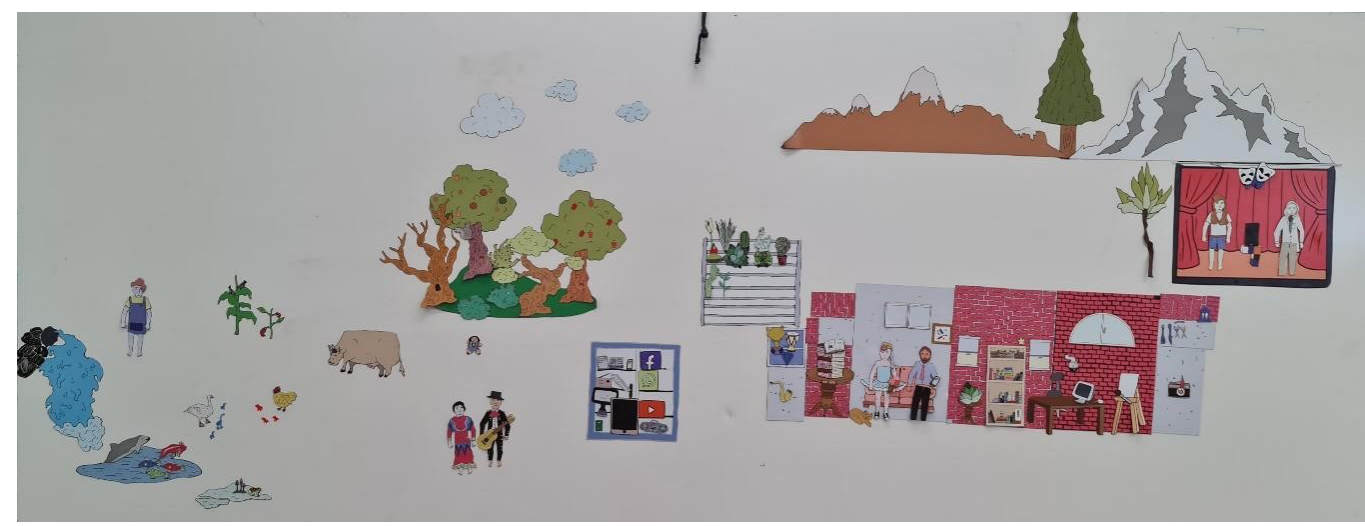

Elaborado por "niña 1" (2021).

Al momento del primer reporte de resultados, la comunidad de indagación ha avanzado en la construcción de una primera matriz o base de datos con diferentes entradas: temáticas presentes en la representación de los mundosideales; intereses, gustos y habilidades de cada niño y niña; datos sociodemográficos e información sobre el uso de las TIC, etcétera. Se realizó, asimismo, una categorización. En cuanto a la evaluación contextual y del análisis de las entrevistas se obtuvo el perfil sociodemográfico de padres y madres de familia (edad, escolaridad, ámbito laboral, estructura familiar, etcétera). Todo este se realizó porque se parte de la idea de que el seguimiento escolar que reciben en casa por parte de los padres o madres es fundamental en su proceso de aprendizaje de la lectoescritura y en la supervisión sobre el uso adecuado de las TIC, pero además porque se parte del supuesto de que los contextos familiares, particularmente acciones cotidianas o hábitos de convivencia con los miembros del hogar, pueden incidir en los imaginarios sobre sus mundos ideales y en la percepción social de la niñez, tal y como lo demuestran sus representaciones por medio de imanes, dibujos y 
cuentos ( $p$. ej. trofeos en casa, tener más integrantes en la familia, conocer el cine, regar las plantas, cuidar y alimentar a los animales de la calle, etcétera). Los participantes que realizaron representación por medio de imanes tuvieron un espacio para conocer y organizar los elementos disponibles, posteriormente recibieron la consigna "construye tu mundo ideal usando los imanes disponibles, si necesitas representar algo que no se encuentre aquí, puedes hacerlo usando marcadores". Para los participantes que realizaron dibujo, la consigna fue "en esta hoja en blanco, dibuja tu mundo ideal, puedes usar las hojas que necesites y los lápices de colores que gustes", previo a la consigna los niños y niñas compartieron su percepción sobre "mundo ideal".

La composición familiar en los hogares es diversa. Los datos sociodemográficos y familiares obtenidos demuestran que el tejido de la sociedad contemporánea en la población de estudio presenta diferentes aristas: parejas en unión libre, padre y madre separados, madres solteras, hogares con jefatura femenina, familias extensas, etcétera. Por otro lado, el contexto de las colonias en las que vive y crece cada niño y niña también resulta interesante como una posible dimensión de análisis. A través de sus narraciones verbales o representación por medio de imanes o dibujo, algunos niños y niñas reflejan diferentes problemáticas que aquejan el entorno donde viven: venta de drogas, maltrato animal, basura en las calles, calles sin pavimento; así como otras circunstancias generalizadas como inseguridad, violencia, discriminación, migración, etcétera. El panorama en cuanto a la disponibilidad y accesibilidad a las TIC también es diverso. De acuerdo con las entrevistas, los niños y niñas disponen de internet (plan de renta o datos móviles) y al menos un teléfono celular (que puede ser propio o prestado eventualmente por el papá o mamá para conectarse por Meet, WhatsApp o para investigar tareas, etc.), aunque la constante es que el internet suele ser deficiente en la mayoría de las colonias. De los 8 niños y niñas entrevistados, 4 cuentan con laptop, sobre todo a raíz del contexto de las clases a distancia, y en ocasiones es compartida por otros miembros del hogar; 1 dispone de computadora de escritorio; 1 puede hacer uso de diferentes computadoras o laptop que hay en casa; 2 no disponen de computadora o laptop para conectarse y hacer sus trabajos, sólo de teléfono celular. Aun con esta diversidad en cuanto a recursos tecnológicos, en los 8 niños y niñas participantes existe una influencia generalizada de las redes sociales y aplicaciones, como WhatsApp, Facebook, YouTube, entre otras. Esta información es significativa desde el punto de vista de la inequidad en el acceso a las TIC en el contexto de las clases a distancia, aprovechamiento y rezago en los aprendizajes, pero también en términos de otros usos y riesgos de las TIC más allá del contexto propiamente escolar.

Por último, se ofrece un primer reporte de los mundos ideales representados por cada niño y niña a través del uso de imanes, dibujos y cuentos; y una descripción sobre sus intereses, gustos y habilidades. Algunos de los temas predominantes que se identificaron y clasificaron por la comunidad de indagación son: 1) Cuidado a los animales (no maltrato animal, no animales en las calles, comida, caminos 
y casas para los animales de la calle, tener más perros en casa, cuidar a los pollitos, etc.); 2) Ecología, cuidado del medio ambiente y naturaleza (cuidar el agua, no contaminación del agua y del aire, no basura en las calles, recolección de basura); 3) Sustentabilidad (árboles y huertos frutales para las personas pobres o de la calle, trueque de recursos básicos en la alimentación); 4) Tecnologías (energías limpias, internet, videojuegos); 5) Familia (tener más integrantes, tener a sus bisabuelos); 6) Valores (paz, respeto, inclusión, equidad, etc.); 6) Educación (estudiar una carrera); 7) Migración (que no existan fronteras entre países); y 8) Problemas sociales A) Discriminación o racismo (a adultos mayores, migrantes, discapacitados o personas de otro color y cultura); y B) Violencia, inseguridad, secuestros, robos, corrupción.

Los gustos, intereses y habilidades de los niños y niñas también son un aspecto para considerar en la intervención por medio de lecturas guiadas y en las cuales ellos puedan sentirse partícipes en la construcción del mundo de sus sueños a partir de lo que les gusta y saben hacer. Con esto, proponemos, se favorecerá una visión emancipadora e incluyente. Los gustos, intereses y habilidades que se identificaron se clasificaron de la siguiente manera: 1) Artes (pintar, dibujar, cantar, música, moda); 2) Habilidades lingüísticas (escribir, leer, platicar); 3) Géneros literarios (terror, ficción, comics, leyendas, fábulas); 4) Contenidos curriculares y extracurriculares (español, inglés, matemáticas, historia, geografía, ciencias, banda de guerra); 5) Pasatiempos (construir con legos, jugar videojuegos, resolver acertijos); y 6) TIC (seguir a YouTubers, Streamers, ver caricaturas y documentales, resolver retos de internet, jugar videojuegos, dominar celular y tableta, etcétera).

A grandes rasgos, ésta es parte de la información cualitativa que se obtuvo a partir de la evaluación diagnóstica y contextual, misma que está siendo procesada en una base de datos. Esta información está a disposición del grupo interdisciplinar que reflexionará sobre los datos, seleccionará las lecturas e intervendrá en la mediación lectora; pero también está disponible para todos los participantes con la intención de comunicarles los primeros hallazgos, y juntos avanzar en un empoderamiento de la niñez que participa en este proyecto de investigación e incidencia.

\section{Conclusiones}

Aunque la pandemia hizo dudar de la posibilidad de realizar la primera fase del trabajo de campo, se pugnó por todos los medios para hacerlo, pues se consideró que era indispensable al menos un primer ejercicio piloto no sólo para cumplir con lo comprometido ante Conacyt, sino para validar la posibilidad de aplicar los instrumentos diagnósticos de manera presencial o de manera online (en línea). Se había invertido ya demasiado tiempo como para frustrarse con la emergencia, por lo que fue muy oportuna la relativa reactivación de algunas actividades escolares en el nivel básico. Algunas de las sesiones de la comunidad de indagación se 
dedicaron a explorar las posibilidades de la aplicación del diagnóstico en línea. Luego del diagnóstico piloto presencial se hizo evidente que una aplicación de esta naturaleza hubiese sido un fracaso, puesto que la mayoría de los participantes toman clase únicamente utilizando el teléfono celular y con mala conexión a internet: el tamaño de la pantalla y eventuales desconexiones lo habrían hecho imposible.

Se planteó inicialmente que el espacio en el que se realizaría el diagnóstico sería la propia escuela de los niños. Con los cambios en el espacio de aplicación, se encontró que el sacarlos de su escuela permite hacer una aplicación más individualizada haciendo que se ponga más atención a cada participante y sobre todo aprovechar la presencia de los padres para entrevistarlos, sin requerir citarlos de manera posterior.

La pandemia impidió que los miembros del equipo de investigación que viven en otras ciudades pudieran acudir al diagnóstico, como se tenía previsto. La idea era que la experiencia también sirviese como capacitación para la realización del diagnóstico (cuando sea posible) en Guadalajara o en otros espacios. Esto, además, nos hubiese permitido conocernos en persona, pues con algunos no se ha dado aún la oportunidad. La relación personal entre los miembros de la comunidad de indagación se considera fundamental para el éxito del proyecto. Algunas sesiones se dedicaron exclusivamente a tratar de uniformar la visión del proyecto con los intereses de cada uno de los miembros, entre los cuales destaca el querer hacer algo para cambiar el estado de las cosas y apoyar a los niños y niñas a mejorar su capacidad de aspirar y a desarrollar herramientas para incluir y ser incluidos.

En conclusión, el Covid-19 dio más tiempo para la integración del equipo de trabajo, para hacer más lecturas y explorar posibilidades. La prórroga que se dio tanto de manera oficial como extraoficial (el retraso en la formalización del proyecto por parte del Conacyt) fue benéfica pero hizo correr el riesgo de resultar no sólo cansada sino estéril. Al final, afortunadamente, eso no ocurrió y ha dejado muchas cosas positivas. La experiencia de la adaptación ha resultado igualmente útil para prever los futuros desarrollos del diagnóstico y sus posibilidades a futuro.

\section{Agradecimientos}

Este proyecto ha sido financiado por el Consejo Nacional de Ciencia y Tecnología (Conacyt) de México, al cual se le ofrecen créditos y agradecimientos 
"Mundos ideales", un proyecto de investigación e incidencia en el contexto de la pandemia del COVID-19 en

México por Luis A. Pérez A., Verónica C. Macías E., José I. Campos C., Rosa M. Alonzo G. y Martha G. Mendoza C.

\section{Referencias bibliográficas}

Álvarez-Gayou Jurgenson, J. L. (2003). Cómo hacer investigación cualitativa. Paidós.

Angrosino, M. (2012). Etnografía y observación participante en Investigación Cualitativa. Morata.

Ardévol, E. \& Muntañola, N. (coords.)(2004). Representación y cultura audiovisual en la sociedad contemporánea. Editorial UOC.

Arizpe, E. \& Styles, M. (2016). Children reading picturebooks. Creative and critical responses to visual texts. Routledge.

Bocaranda-Santos, R. A. (2009). La comunidad de indagación. Forjadora de la nueva sociedad. Revista de Artes y Humanidades UNICA, 10(2), 211-217. https://www.redalyc.org/pdf/1701/170118863011.pdf

Casas, F. (1998). Infancia: Perspectivas psicosociales. Paidós.

Cassany, D. (2005). Investigaciones y propuestas sobre literacidad actual: multiliteracidad, internet y criticidad. Cátedra Unesco para la lectura y la escritura: Universidad de Concepción de Chile. http://www2.udec.cl/catedraunesco/05CASSANY.pdf

Conacyt (2019a, 22 de noviembre). Convocatoria 2019 para la elaboración de propuestas de proyectos de investigación e incidencia orientados al fomento de la lectoescritura como estrategia para la inclusión social. https://www. conacyt.gob.mx/index.php/el-conacyt/convocatorias-y-resultados-conacyt/ convocatorias-fordecyt/convocatorias-abiertas-fordecyt/fordecyt-201908/19526-convocatoria-fordecyt-2019-08/file

Conacyt (2019b). Anexo 2. Términos de referencia. Convocatoria 2019 para la elaboración de propuestas de proyectos de investigación e incidencia orientados al fomento de la lectoescritura como estrategia para la inclusión social. https://www.conacyt.gob.mx/index.php/el-conacyt/convocatoriasy-resultados-conacyt/convocatorias-fordecyt/convocatorias-abiertasfordecyt/fordecyt-2019-08/19524-terminos-fordecyt-2019-08/file

Conacyt (2020, 4 de mayo). Publicación de Resultados Convocatoria 2019-08 para la elaboración de propuestas de proyectos de investigación e incidencia orientados al fomento de la lectoescritura como estrategia para la inclusión social. https://www.conacyt.gob.mx/index.php/el-conacyt/convocatoriasy-resultados-conacyt/convocatorias-fordecyt/convocatorias-abiertasfordecyt/fordecyt-2019-08/19940-resultados-fordecyt-conv-2019-08/file 
Conacyt (s/f). ¿Qué son los Pronaces?

https://www.conacyt.gob.mx/index.php/que-son-los-pronaces

DOF [Diario Oficial de la Federación] (2020, lunes 30 de marzo). Acuerdo por el que se declara como emergencia sanitaria por causa de fuerza mayor, a la epidemia de enfermedad generada por el virus Sars-Cov2 (COVID-19). https:// www.gob.mx/cjef/documentos/se-declara-como-emergencia-sanitaria-laepidemia-generada-por-covid-19

Dulama, M., Ilovan, O-R. \& Vanea, C. (2009). Several characteristic features of children's representation. Acta Didáctica Napocensia, 2(4), 75-90. https://files.eric.ed.gov/fulltext/EJ1052264.pdf

EFE (2021, 1 de marzo). Estudiantes de Jalisco regresan a las aulas tras un año de clases virtuales. El Informador. https://www.informador.mx/jalisco/ Estudiantes-de-Jalisco-regresan-a-las-aulas-tras-un-ano-de-clasesvirtuales-20210301-0077.html

Evans, J. (2015). Challenging and controversial picturebooks. Creative and critical responses to visual texts. Routledge.

Gobierno de Jalisco (2020, 16 de marzo). Anuncia SE medidas tras la suspensión de clases para evitar la propagación del Covid-19 en Jalisco. https://www.jalisco.gob.mx/es/prensa/noticias/102614

Groenke, S. L. \& Prickett, R. (2012). Continued absences: Multimodal texts and 21st century literacy instruction. ALAN Review, 39, 62-67. https://doi.org/10.21061/alan.v39i2.a.9

Jiménez, C. \& Mancinas, R. (2009). Semiótica del dibujo infantil: una aproximación latinoamericana sobre la influencia de la televisión en los niños: casos de estudios en ciudades de Chile, El Salvador y México. Arte, individuo y sociedad, 21, 151-164. https://revistas.ucm.es/index.php/ARIS/article/view/6608

Luna-Reyes, D., Herrera-Mijangos, S. A. \& Escobar, J. G. (2019). Niñez y migración: propuesta cualitativa desde dibujos temáticos y narraciones. Revista PSICUMEX, 9(1), 37-55. https://doi.org/10.36793/psicumex.v9i1.157

Mannay, D. (2017). Métodos visuales narrativos y creativos en investigación cualitativa. Narcea Ediciones.

Martínez, L. (2017). Socialización diferenciada por razón de género en educación infantil: un estudio etnográfico. Revista Complutense de Educación. https://doi.org/10.5209/RCED.54263 
"Mundos ideales", un proyecto de investigación e incidencia en el contexto de la pandemia del COVID-19 en México por Luis A. Pérez A., Verónica C. Macías E., José l. Campos C., Rosa M. Alonzo G. y Martha G. Mendoza C.

Martínez-Ezquerro, A. \& Martos, A. (2018). La lectura en los actuales contextos de educación social. Claves desde la formación literaria. Pedagogía Social. Revista Interuniversitaria, 33, 19-30. https://doi.org/10.7179/PSRI_2019.33.01

Rodríguez, S. (1986). Salud mental del niño de 0 a 12 años. El aparato psíquico y los estados de ansiedad en la niñez. UENED.

NU [Naciones Unidas] (2020, 14 de julio). La Agenda para el Desarrollo Sostenible. https://www.un.org/sustainabledevelopment/es/development-agenda/

UNICEF (2013, noviembre). Superando el adultocentrismo. Santiago de Chile: Fondo de las Naciones Unidas para la Infancia. https://www.imageneseducativas. com/wp-content/uploads/2019/02/Superando-el-Adultocentrismo.pdf

UNICEF (2016, junio). Estado mundial de la infancia 2016. Una oportunidad para cada niño. Nueva York: Fondo de las Naciones Unidas para la Infancia. https:// www.unicef.org/spanish/publications/files/UNICEF_SOWC_2016_Spanish.pdf

UNICEF (s/f). Texto de la Convención sobre los Derechos de los Niños.

https://www.unicef.org/es/convencion-derechos-nino/texto-convencion

Vaca, A. (2000). La fuerza de la tradición oral. Revista de Estudios Jaliscienses, 40, 48-63.

Vasilachis, I. (2006). Estrategias de investigación cualitativa. Gedisa.

Vega Casanova, M. J. \& García, L. H. (2005). Imaginarios de ciudad en niños y niñas de Barranquilla-Colombia. Quórum Académica, 2(1), enero-junio, 3760. https://www.redalyc.org/articulo.oa?id=199016758002

Villanen, H. \& Jonsson, G. (2013). Envisioning the future- A question of distance. International Electronic Journal of Environmental Education, 3(1), 1-16. https://files.eric.ed.gov/fulltext/EJ1104819.pdf

Dirección de correspondencia:

Luis Alberto Pérez-Amezcua

Contacto: perez.amezcua@cusur.udg.mx

Esta obra se encuentra bajo una Licencia de Creative Commons

Reconocimiento-NoComercial-Compartirlgual 4.0 Internacional 